\title{
AVALIAÇÃO DAS PROPRIEDADES BIOQUÍMICAS E CINÉTICAS DE LIPASE MICROBIANA IMOBILIZADA EM COPOLÍMERO DE ESTIRENO DIVINILBENZENOMAGNETIZADO
}

\author{
C. F. Do PRADO ${ }^{1}$, H. B. S. BENTO ${ }^{1}$, P. C. OLIVEIRA ${ }^{1}$, H. F. De CASTRO ${ }^{1}$, L. FREITAS ${ }^{1}$ \\ ${ }^{1}$ Universidade de São Paulo, Escola de Engenharia de Lorena, Departamento de Engenharia \\ Química \\ E-mail para contato: cintia@alunos.eel.usp.br
}

\begin{abstract}
RESUMO - A imobilização de lipases em matrizes híbridas visando à obtenção de biocatalisadores ativos, estáveis e de baixo custo, vem se destacando como uma alternativa para o desenvolvimento sustentável, de química verde ou de tecnologia limpa. Neste contexto, o objetivo deste trabalho foi avaliar as propriedades bioquímicas e cinéticas da lipase de Candida rugosa imobilizada em suporte de copolímero de estireno-divinilbenzeno magnetizado pela inserção de partículas de óxido de ferro, visando a substituição dos tradicionais catalisadores químicos e possível aplicação industrial. Para tanto, o desempenho do biocatalisador magnetizado foi comparado com a lipase livre e imobilizada em suporte de poli(estireno-co-divinilbenzeno) não magnetizado, sendo caracterizados em função das melhores condições de operação em $\mathrm{pH}$ e temperatura, determinação das constantes cinéticase estabilidade térmica. Os resultados sugeriram que o derivado magnetizado possui grande potencial de aplicação, apresentando $\mathrm{Km}$ de 1766,57 mM, Vmáx de 5870,08 U g ${ }^{-1}$,elevada estabilidade térmica $\left(\mathrm{Kd}=0,068 \mathrm{~h}^{-}\right.$ 1) e tempo de meia vida de 10,2h, comprovando assim a boa estabilidade do biocatalisador. Além disso, a incorporação de partículas magnéticas facilita sua separação do meio e possibilita sua reutilização de modo eficiente.
\end{abstract}

\section{INTRODUÇÃO}

As exigências para que as indústrias operem seus processos em condições de desenvolvimento sustentável, são cada vez mais importantes em várias partes do mundo, e tornam-se um obstáculo a ser superado sem a disponibilidade de biocatalisadores adaptados a estas condições (Polshettiwar et al., 2011; Verma; Barrow; Puri, 2013). Assim, o uso de processos enzimáticos em substituição às rotas químicas tradicionais desponta como uma alternativa para a obtenção de produtos não agressivos do ponto de vista ecológico.

Nesse contexto, a imobilização de lipases em suportes sólidos torna essa área ainda mais promissora, atribuindo maior estabilidade ao biocatalisador, permitindo operações em regime contínuo, melhor dispersão no meio reacional e sobretudo, a capacidade de reutilização (Paula et al., 2008). Dentre os métodos de imobilização mais usados atualmente estão: a ligação cruzada; a encapsulação; as ligações covalentes e a adsorção, sendo essa última a mais simples e comumente aplicada (Lima et al., 2001). 
Atualmente os materiais híbridos magnetizados vêm sendo muito utilizados como matrizes de imobilização, devido a facilidade de recuperação do biocatalisador por separação magnética (Lee et al., 2003), otimizando o processo. Dessa maneira, o objetivo do presente trabalho foi imobilizar a lipase de Candida rugosa em um suporte de copolímero de estireno e divinilbenzeno magnetizado com partículas de óxido de ferro e caracterizar o biocatalisador obtido quanto às suas propriedades bioquímicas e cinéticas, visando futuras aplicações.

\section{METERIAIS E MÉTODOS}

\subsection{Materiais}

Foi usada a lipase microbiana de Candida rugosa (tipo VII, Sigma-Aldrich ${ }^{\circledR}$ ) na forma livre e imobilizada através de adsorção física em copolímero de estireno-divinilbenzeno magnetizado (STY-DVB-M) e não magnetizado (STY-DVB). Para a imobilização e realização das dosagens de atividade enzimática foram utilizados os seguintes materiais de partida: n-heptano (Cromoline), polietilenoglicol - PEG (Synth - MM 1500), azeite de oliva comercial com baixo teor ácido (Carbonell) e goma arábica em pó pura (Synth).

\subsection{Síntese dos suportes poliméricos (STY-DVB e STY-DVB-M)}

Os suportes de STY-DVB foram sintetizados através da técnica de polimerização em suspensão utilizada por Oliveira et al. (2000), tendo o suporte STY-DVB-M recebido a adição de $10 \%(\mathrm{~m} / \mathrm{m})$ de magnetita obtida pelo método de co-preciptação dos íons $\mathrm{Fe}^{+2}$ e $\mathrm{Fe}^{+3}$ em meio básico, tratada com ácido oleico segundo a metodologia descrita por Lee et al. (2003). As partículas obtidas foram peneiradas e as retidas entre as peneiras de 24 e 35 Mesh (Tyler) foram escolhidas para a realização da imobilização.

\subsection{Imobilização de lipase Candida rugosa nos suportes poliméricos}

A imobilização foi realizada através de adsorção física, em uma proporção de $0,25 \mathrm{~g}$ de enzima para $1 \mathrm{~g}$ de suporte com adição de $100 \mu \mathrm{l}$ de polietilenoglicol por grama de suporte. $\mathrm{O}$ sistema permaneceu conservado por $24 \mathrm{~h} \mathrm{a} 4^{\circ} \mathrm{C}$ e o biocatalisador foi recuperado por filtração à vácuo seguido de lavagens com heptano até umidade inferior a 15\% (Oliveira et al., 2000).

\subsection{Dosagem da atividade hidrolítica}

O método da hidrólise de azeite de oliva de Soares et al. (1999) foi utilizado para a dosagem da atividade hidrolítica dos suportes imobilizados (STY-DVB e STY-DVB-M) e da enzima livre. $\mathrm{O}$ rendimento de imobilização $(\eta \%)$ foi calculado pela relação de unidades de atividade fornecida para imobilização e a quantidade recuperada pelo imobilizado.

\subsection{Caracterização das propriedades bioquímicas e cinéticas}

Para a determinação da cinética das reações de hidróliseforam utilizadas concentrações variáveis de substrato - 10 a $50 \%(\mathrm{~m} / \mathrm{v})$ de azeite de oliva em relação à solução aquosa de goma arábica $(7 \% \mathrm{~m} / \mathrm{v})$. O software Hyper 32 foi utilizado para calcular os parâmetros cinéticos ( $\mathrm{Km}$ e Vmáx). As propriedades bioquímicas, como influência do $\mathrm{pH}$ e da 
temperatura na atividade hidrolítica da lipase de Candida rugosa (LCR)livre e dos derivados imobilizados, foram avaliadas por um planejamento estatístico $2^{2}$ estrela rotacional com quatro replicatas no ponto central $\left(45^{\circ} \mathrm{C} \mathrm{e} \mathrm{pH}=7\right)$. Os níveis reais e codificados das variáveis em estudo estão apresentados na Tabela 1, sendo os resultados analisados pelos softwares Statistica 12.0 (StatSoft Inc., USA) e Design-Expert 9.0 (Stat-Ease Corporation, USA).

Tabela 1 - Níveis utilizados no planejamento estatístico

\begin{tabular}{lccccc}
\hline & Alfa(-) & Nível baixo & Ponto central & Nível alto & Alfa $(+)$ \\
\hline Temperatura $\left({ }^{\circ} \mathrm{C}\right)$ & 31 & 35 & 45 & 55 & 59 \\
$\mathrm{pH}$ & 5,6 & 6,0 & 7,0 & 8,0 & 8,4 \\
\hline
\end{tabular}

\subsection{Estabilidade térmica}

A enzima livre e os derivados imobilizados foram incubados em meio de heptano a $60^{\circ} \mathrm{C}$ em intervalos de tempo entre 15 e $180 \mathrm{~min}$. Amostras foram retiradas e suas atividades residuais medidas, tomando-se o valor obtido no tempo zero como $100 \%$. As Equações (1) e (2) forneceram o coeficiente de desativação $(\mathrm{kd})$ e tempo de meia vida $\left(\mathrm{t}_{1 / 2}\right)$, em que $\mathrm{A}_{0}=$ atividade inicial e $\mathrm{A}=$ atividade residual.

$$
\begin{aligned}
& \ln A=\ln A_{0}-k d \times t \\
& t_{\frac{1}{2}}=\frac{\ln 2}{k d}
\end{aligned}
$$

\section{RESULTADOS E DISCUSSÃO}

\subsection{Atividades hidrolíticas e rendimento de imobilização}

As atividades hidrolíticas e os rendimentos de imobilização obtidos para os biocatalisadores testados encontram-se na Tabela 2. Os elevados valores das atividades hidrolíticas e de rendimento de imobilização indicam a eficiência do processo de imobilização e o efetivo potencial de aplicação do suporte STY-DVB-M, visto que a lipase imobilizada neste suporte apresentou os maiores valores para esses dois parâmetros. Este fato pode ser explicado pela menor perda de massa durante o processo de imobilização devido a fácil recuperação deste biocatalisador através da aplicação de um campo magnético externo.

Tabela 2 - Atividade hidrolítica e Rendimento de imobilização dos biocatalisadores

\begin{tabular}{ccc}
\hline Lipase de Candida rugosa * & Rendimento de Imobilização ( $\%$ ) & Atividade (U g $\left.{ }^{-1}\right)$ \\
\hline Imobilizada em STY-DVB & 69 & $1292 \pm 66$ \\
Imobilizada em STY-DVB-M & 89 & $1456 \pm 71$ \\
\hline
\end{tabular}

* No processo de imobilização foram fornecidas $2000 \mathrm{U}$ de lipase livre por grama de suporte

\subsection{Determinação dos parâmetros bioquímicos}

Um planejamento estatístico $2^{2}$ estrela rotacional foi realizado para obter as condições ótimas de $\mathrm{pH}$ e temperatura para os biocatalizadores testados. A variação nos valores de 
atividade hidrolítica foi de 10597 a18003 U.g-1 para a lipase livre, de 2232 a $2771 \mathrm{U}^{-1} \mathrm{~g}^{-1}$ para a lipase imobilizada no suporte STY-DVB e de 1683 a $2908 \mathrm{U} \cdot \mathrm{g}^{-1}$ para a lipase imobilizada no suporte STY-DVB-M. Nota-se que a enzima livre apresentou maior variação em sua atividade, em comparação aos derivados imobilizados, demonstrando que a imobilização gerou maior estabilidade, mantendo os níveis de atividade sob condições mais amplas. A Figura 1 (a-c) trás os gráficos de Pareto da análise estatística dos efeitos ( $\mathrm{t}$ calculado em relação a t tabelado, com $95 \%$ de confiança) relacionados à influência de $\mathrm{pH}$ e da temperatura na atividade hidrolítica da lipase livre e imobilizada nos suportes. A partir da análise da Figura 1a pode-se prever o comportamento da lipase livre, sendo que o aumento do $\mathrm{pH}$ gera uma influência positiva na atividade hidrolítica (tanto o efeito linear como o quadrático), enquanto que a relação com a temperatura não é determinante.

Figura 1 - Gráficos de Pareto para a) LCR livre, b) STY-DVB e c) STY-DVB-M

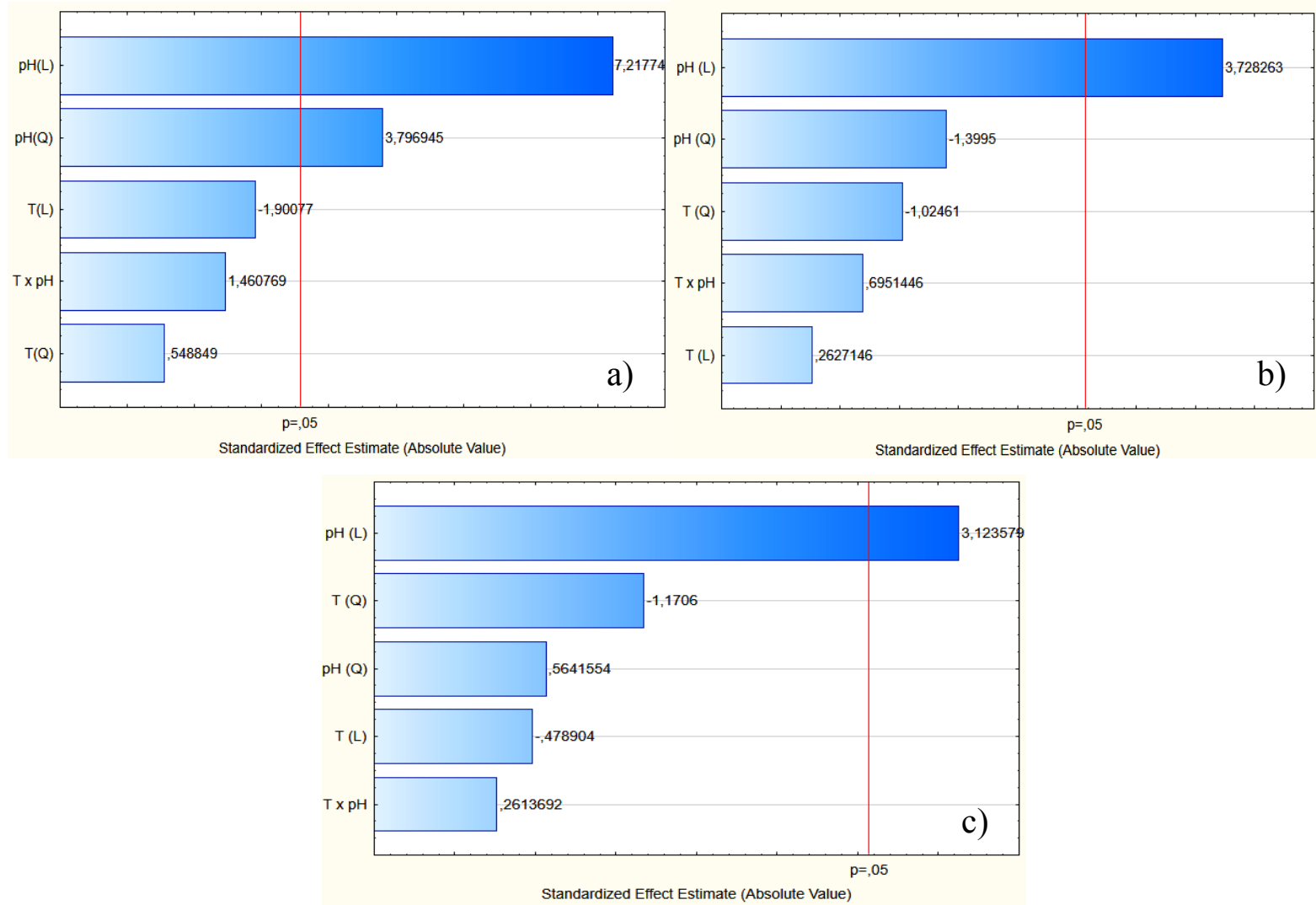

Observando-se as Figuras $1 \mathrm{~b}$ e 1c, percebe-se a mesma tendência observada para a enzima livre, ou seja, na referida faixa de temperatura não houve significativa alteração no processo de hidrólise. Apenas a mudança de $\mathrm{pH}$ acarretou uma variação considerável, sendo que quanto maior a basicidade do meio, maior a atividade hidrolítica. O ponto ótimo para o $\mathrm{pH}$ foi próximo a 8 , valor que corrobora com resultados anteriores de caracterização desta mesma lipase que apontaram uma faixa de pH ótimo entre 7 e 8 (Paula et al., 2008).

\subsection{Determinação dos parâmetros cinéticos}

$\mathrm{O}$ perfil das atividades hidrolíticas realizadas a $45^{\circ} \mathrm{C}$ e $\mathrm{pH}=8$ para os três sistemas testados está representado graficamente na Figura 2 (a-c). Os parâmetros cinéticos foram 
determinados a partir desses resultados, considerando a cinética de Michaellis-Menten e empregando o software Hyper 32 para ajuste dos dados experimentais.

Figura 2 - Perfil de atividades hidrolíticas $\left(\mathrm{U} \cdot \mathrm{g}^{-1}\right) \times$ concentração $\left(\mathrm{mmol} \cdot \mathrm{L}^{-1}\right)$.
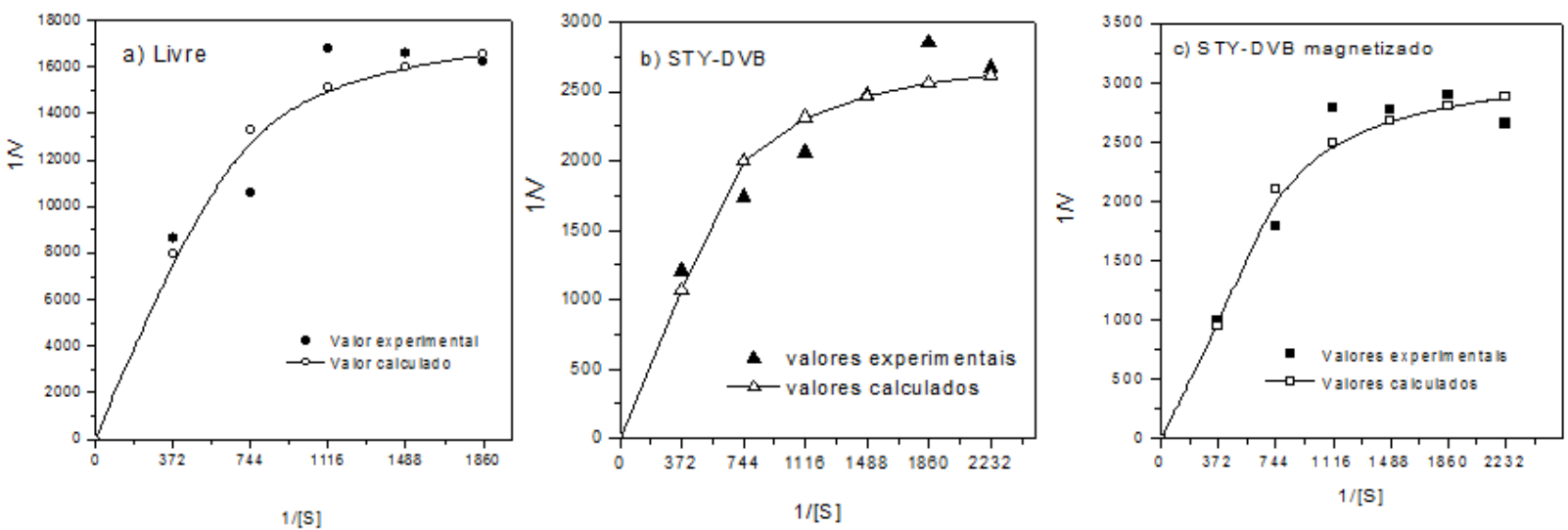

Os valores de Km e Vmáx foram calculados pela Equação 3 e mostrados na Tabela 3.

$$
\frac{\mathbf{1}}{V}=\frac{K m}{V m \mathbf{a} x} \frac{\mathbf{1}}{[S]}+\frac{\mathbf{1}}{V m \mathbf{a} x}
$$

Tabela 3 - Valores de Km e Vmáx para os três sistemas avaliados

\begin{tabular}{ccc}
\hline Sistema & Vmáx $\left(\mathrm{U}^{-1} \mathrm{~g}^{-1}\right)$ & $\mathrm{Km}(\mathrm{mM})$ \\
\hline LCR Livre & 22576 & 626 \\
LCR imobilizada em STY-DVB & 3699 & 781 \\
LCR imobilizada em STY-DVB-M & 5870 & 1767 \\
\hline
\end{tabular}

O maior valor de Km verificado pelo derivado imobilizado magnetizado indica redução da afinidade da lipase pelo substrato. Esse fato pode ser justificado pela incorporação das nanopartículas de óxido de ferro no suporte híbrido, sugerindo limitação difusional do substrato ao sítio ativo da enzima, devido à presença da magnetita.

\subsection{Estabilidade térmica}

A Tabela 4 mostra os parâmetros de de desativação térmica $(\mathrm{kd})$ e tempo de meia vida $\left(\mathrm{t}_{1 / 2}\right)$ para a enzima livre e derivados imobilizados incubados a $60^{\circ} \mathrm{C}$. O decaimento de atividade hidrolítica da LCR livre após 15 minutos de incubação foi significativo, enquanto os derivados imobilizados demonstraram maior estabilidade térmica. O maior tempo de meia vida foi encontrado para o derivado magnetizado (cerca de 10h), indicando a formação de ligações estáveis entre a enzima e o suporte magnético no processo de imobilização, melhorando assim a estabilidade térmica desse biocatalisador quando comparado ao imobilizado não magnético. Além disso, o tempo de meia vida obtido para LCR imobilizada em STY-DVB-M foi superior ao obtido em trabalho realizado por Simões et al. (2011), que imobilizou essa mesma lipase em uma matriz de $\mathrm{SiO}_{2}$-quitosana $\left(\mathrm{t}_{1 / 2}=1,63 \mathrm{~h}\right)$. 
Tabela 4- Constante de desativação térmica e tempo de meia vida dos biocatalisadores

\begin{tabular}{ccc}
\hline Sistema & ${\mathrm{kd}\left(\mathrm{h}^{-1}\right)}$ & $\mathrm{t}_{1 / 2}(\mathrm{~h})$ \\
\hline LCR Livre & 3,46 & 0,2 \\
LCR imobilizada em STY-DVB & 0,10 & 6,8 \\
LCR imobilizada em STY-DVB-M & 0,07 & 10,2 \\
\hline
\end{tabular}

\section{CONCLUSÃO}

Os resultados indicam grande potencial de aplicação do biocatalisador magnético, uma vez que a incorporação de partículas magnéticas não prejudicou sua atuação catalítica, além de contribuir para o aumento do rendimento de imobilização e facilitar a sua separação e recuperação do meio reacional a partir da utilização de um campo magnético externo. Constatou-se que o biocatalisador magnético possui $\mathrm{pH}$ ótimo próximo a 8 e atuação catalítica estável em uma ampla faixa de temperatura. Além disso, este derivado imobilizado revelou um elevado tempo de meia-vida (10,2 h), mostrando que a imobilização estabilizou termicamente a lipase de Candida rugosa no suporte de estireno-divinilbenzeno magnetizado.

\section{REFERÊNCIAS BIBLIOGRÁFICA}

LEE, Y.; RHO, J.; JUNG, B. Preparation of Magnetic Ion-Exchange Resins by the Suspension Polymerization of Styrene with Magnetite.J. Appl. Polym.Sci., v. 89, p. 2058-2067, 2003.

LIMA U.A.; BORZANI,W.; SCHIMIDELL, W.; AQUARONE, E. Biotecnologia IndustrialProcessos fermentativos e enzimáticos. São Paulo: Editora Edgard BlucherLtda, 2001.

OliVeIRA, P.C.; ALVES, G.M.; De Castro, H.F.; Mei, L.H.I. Síntese do Butirato de n-Butila empregando Lipase Microbiana Imobilizada em Copolímero de Estireno-Divinilbenzeno. Quim. Nova, v. 23, p. 632-636, 2000.

PAULA, A.V.; MOREIRA, A.B. R.; BRAGA, L.P.; DE CASTRO, H.F.; BRUNO, L.M., Comparação do desempenho da lípase de Candida rugosa imobilizada em suporte híbrido de polissiloxanopolivinilálcool empregando diferentes metodologias. Qui. Nova, v. 31, p. 35-40, 2008.

POLSHETTIWAR, V.; LUQUE, R.; FIHRI, A.; ZHU, H.; BOUHRARA, M.; BASSET, J.M. Magnetically Recoverable Nanocatalysts. Chemical Reviews, v. 111, p. 3036-3075, 2011.

SIMÕES, A.S.; MORI, R.Y.; FARIA, R.; DE CASTRO, H.F.; MENDES, A.A. Desempenho da matriz híbrida $\mathrm{SiO}_{2}$-quitosana na imobilização de lipase microbiana de Candida rugosa. Quí. Nova, v. 34, São Paulo, 2011

SOARES, C.M.F.; DE CASTRO, H.F.; MOARES, F.F.; ZANIN, G.M., Characterization and utilization of Candida rugosa lipase immobilized on controlled pore silica. Appl. Biochem. Biotechnol., v. 77, p. 745-757, 1999.

VERMA, M.L.; BARROW, C.J.; PURI, M. Nanobiotechnology as a novel paradigm for enzyme immobilisation and stabilisation with potential applications in biodiesel production. Applied Microbiology Biotechnology, v. 97, p. 23-39, 2013. 